\title{
Efeito da Densidade e Proporção de Plantas de tomate INDUSTRIAL E DE MARIA-PRETINHA EM COMPETIÇÃO ${ }^{1}$
}

\author{
Density and Proportion Effects of Industrial Tomato and Nightshade Plants Under Competition
}

\author{
HERNANDEZ, D.D. ${ }^{2}$, ALVES, P.L.C.A. ${ }^{3}$ e SALGADO, T.P. ${ }^{2}$
}

\begin{abstract}
RESUMO - O presente trabalho foi realizado com o objetivo de quantificar as interações competitivas e os índices de competitividade entre plantas de tomate industrial (Lycopersicon esculentum cv. Heinz 9553) e maria-pretinha (Solanum americanum). Usou-se como método um experimento substitutivo, com densidade total de 40 plantas $\mathrm{m}^{-2}$ e 11 proporções, além das monoculturas em densidades, que variaram de 20 a 100 plantas $\mathrm{m}^{-2}$, em intervalos de 20 plantas, conduzidos no delineamento de blocos casualizados com três repetições. Os resultados obtidos foram analisados pelo método convencional de análise de experimentos substitutivos e pela produção recíproca total. A maria-pretinha mostrou ser um competidor mais agressivo que o tomate, sendo mais importante a competição interespecífica para a planta cultivada. Para a biomassa seca total, as duas espécies não competiram pelos mesmos fatores de crescimento. Já para a área foliar, as duas espécies se mostraram competidoras pelos mesmos fatores de crescimento, mostrando ser essa a característica mais sensível à interferência.
\end{abstract}

Palavras-chave: competição intra-específica, competição interespecífica, esquema substitutivo.

\begin{abstract}
This work aimed to quantify the competitive interactions and the competitiveness indexes among plants of industrial tomato (Lycopersicon esculentum cv. Heinz 9553) and nightshade (Solanum americanum). The methodology used was a replacement series experiment with a total density of 40 plants $\mathrm{m}^{-2}$ and 11 proportions, besides the monocultures in densities varying from 20 to 100 plants $\mathrm{m}^{-2}$, in intervals of 20 plants, conducted in a randomized complete block design with three replications. The results were analyzed by the conventional method of analysis of replacement series experiment and for total reciprocal production. The nightshade plant was shown to be a more aggressive competitor than the tomato, with inter-specific competition being more important for the cultivated plant. For the dry aboveground biomasses, the two species did not compete for the same natural resources. For the leaf area, the two species competed for the same growth factors, with this characteristic being the most sensitive to interference.
\end{abstract}

Key words: intraspecific competition, interspecific competition, replacement series experiment.

\section{INTRODUÇÃO}

Sabe-se que a interferência das plantas daninhas nas espécies cultiváveis é de grande importância, e para o tomate esta questão não é diferente. O termo interferência refere-se ao conjunto de ações que recebe uma determinada cultura ou atividade do homem, em decorrência da presença de plantas daninhas num determinado ambiente (Pitelli, 1987).

Muitos são os fatores que afetam o grau de interferência, sendo a densidade de plantas, sem dúvida, um dos mais importantes. Quanto

Recebido para publicação em 15/1/2002 e na forma revisada em 7/8/2002.

2 Eng.-Agr., pós-graduandos em Produção Vegetal da FCAV-UNESP, Jaboticabal-SP, <donatohe@ fcav.unesp.br> e <tpsalgado@ hotmail.com>. ${ }^{3}$ Eng.-Agr., Dr., Professor Assistente do DBAA/FCAV-UNESP, Rod. Prof. Paulo Donato Castellane, s/n, 14884-900 Jaboticabal-SP, <plalves@ fcav.unesp.br. 
maior for a densidade da comunidade infestante, maior será a quantidade de indivíduos que disputa os mesmos recursos do meio e mais intensa será a competição sofrida pela cultura (Pitelli \& Karam, 1988).

Nas áreas de produção agrícola, a densidade das plantas cultivadas é mantida constante, ao passo que a das plantas daninhas varia de acordo com o nível de infestação encontrado no local; dessa forma, obtém-se logicamente variação da proporção entre as espécies daninhas e a cultura. Assim, é fundamental, nos estudos de competição, não medir apenas a influência da densidade de plantas no processo competitivo, mas também a importância da variação na proporção entre as espécies (Christoffoleti \& Victoria Filho, 1996).

A maioria das pesquisas sobre competição entre plantas daninhas e plantas cultivadas determina o período crítico de competição. Por isso, é importante o uso de delineamentos experimentais e metodologias de análise que procurem entender melhor o processo competitivo de forma mais mecanística, e não apenas quantificar perdas (Roush et al., 1989).

Os experimentos substitutivos são uma alternativa para a compreensão do processo competitivo entre plantas, especialmente quando relacionado com o estudo do efeito da densidade e da proporção entre plantas em uma comunidade infestante. Experimentos substitutivos são delineados de tal maneira que existe controle da densidade e proporção das espécies em estudo (Harper, 1977; Wit, 1960), mantendo constante a densidade e variando as proporções das duas espécies. Nesses tipos de experimento, assume-se que a densidade total de plantas é suficientemente grande, de forma que satisfaça a chamada "lei da produção final constante", em que a produção de biomassa por unidade de área é independente da densidade das plantas naquela área (Christoffoleti \& Victoria Filho, 1996).

A interpretação dos dados de um experimento substitutivo resulta na medida da competitividade das espécies baseada na resposta relativa da produção de biomassa pela variação da proporção (Harper, 1977; McGilchrist \& Trenbath, 1974; Wit \& Van Den Bergh, 1965). É possivel calcular equações matemáticas e representações gráficas onde se estabelecem índices de competição intra e interespecífica e diferenciação de nicho ecológico (Spitters, 1983; Joliffe et al., 1984).

Dessa forma, o objetivo deste trabalho foi quantificar a competitividade relativa da cultura do tomate e da planta daninha mariapretinha, por meio da medida do efeito da densidade e da proporção, usando experimento substitutivo.

\section{MATERIAL E MÉTODOS}

Foram conduzidos dois ensaios sob condições semicontroladas, em área experimental pertencente ao Departamento de Biologia Aplicada à Agropecuária (FCAV - UNESP, campus de Jaboticabal). Em ambos, utilizaram-se vasos de cimento-amianto com capacidade para 70 litros (área $=0,24 \mathrm{~m}^{2}$ ), preenchidos com terra coletada na camada arável de um Latossolo Vermelho-Escuro (LE). Foram semeadas sementes das duas espécies (Lycopersicon esculentum cv. Heinz 9553 e Solanum americanum) em bandejas hortícolas (poliestireno) de 128 células, sendo as mudas transplantadas para os vasos aos 45 dias após a semeadura (DAS). Primeiramente, instalou-se um ensaio das monoculturas de tomate e maria-pretinha, ou seja, tratamentos contendo apenas cada uma das espécies, com densidades equivalentes a 20 , 40, 60, 80 e 100 plantas $\mathrm{m}^{-2}$, dispostos em blocos casualizados com três repetições, com o objetivo de determinar uma densidade fixa de plantas $\mathrm{m}^{-2}$ acima da qual não se obtém aumento de produtividade nas duas espécies. Aos 30 dias após o transplante das mudas, determinou-se, para as duas espécies, a biomassa seca de folhas, caule e parte aérea total (folhas + caule), bem como a área foliar dessas plantas, com o aparelho de medição foliar LiCor 3000A. Os dados obtidos foram submetidos à análise de regressão não-linear da produção por $\mathrm{m}^{2}$, como variável dependente $(\mathrm{Y})$, e da densidade, como variável independente (D). A partir das equações matemáticas foram elaborados gráficos de regressão não-linear da produção de biomassa $\mathrm{m}^{-2} \mathrm{e}$ área foliar $\left(\mathrm{cm}^{2}\right)$ em função da densidade. Os dados foram expressos através de hiperbólicas retangulares $\left(\mathrm{Y}=\frac{a \cdot D}{K_{n}+D}\right.$, em que "a" representa a produção final constante para cada espécie). Esse foi o modelo cujos 
dados melhor se ajustaram, seguindo procedimento proposto por Wit \& Van Den Bergh (1965). Desse modelo gráfico obteve-se o coeficiente $K_{n}$, que determina a velocidade de resposta da característica em estudo das espécies em monocultura, em relação à variação da densidade dessas plantas. Esse coeficiente determina, também, a densidade que proporciona produção igual a $50 \%$ da produção final constante. Quanto menor for esse coeficiente para uma determinada cultura, maior é a sensibilidade desta à competição intra-específica.

Após o término do primeiro experimento, instalou-se um segundo, sendo este de esquema substitutivo, contendo uma densidade constante ( 40 plantas $\mathrm{m}^{-2}$ ), porém com tratamentos representando diferentes proporções entre plantas de tomate e maria-pretinha. As proporções foram de 0:40, 4:36, 8:32, 12:28, 16:24, 20:20, 24:16, 28:12, 32:8, 36:4 e 40:0, representando, respectivamente, as densidades de plantas de tomate e maria-pretinha por metro quadrado.

O delineamento experimental adotado também foi o de blocos ao acaso, com 11 tratamentos em três repetições.

Ao término do período experimental (125 dias após a semeadura), avaliou-se a biomassa seca de caules e folhas dessas plantas, além de suas áreas foliares. Os dados foram inicialmente submetidos à análise convencional, na qual os resultados são interpretados visualmente, pela análise de um gráfico contendo a resposta da produção relativa em relação à proporção (Wit, 1960; Wit \& Van Den Bergh, 1965; Harper, 1977). Outro tipo de análise dos resultados do experimento substitutivo foi a metodologia desenvolvida por Spitters (1983), usando a produção média/planta obtida no experimento substitutivo ( $\mathrm{W}=\mathrm{Y} / \mathrm{D}$ ). Os dados provenientes de cada espécie foram então submetidos a uma análise de regressão linear, na forma das equações a seguir:

- $\quad$ Tomate (T):

$$
\frac{1}{W_{T}}=\mathrm{A}_{\mathrm{T}}+\mathrm{B}_{\mathrm{TT}} \times \mathrm{D}_{\mathrm{T}}+\mathrm{B}_{\mathrm{TMP}} \times \mathrm{D}_{\mathrm{MP}}
$$

- Maria-pretinha (MP):

$$
\frac{1}{W_{M P}}=\mathrm{A}_{\mathrm{MP}}+\mathrm{B}_{\mathrm{MPMP}} \times \mathrm{D}_{\mathrm{MP}}+\mathrm{B}_{\mathrm{MPT}} \times \mathrm{D}_{\mathrm{T}}
$$

Os coeficientes de competição intra-específica $\left(\mathrm{B}_{\mathrm{TT}}\right.$ e $\mathrm{B}_{\mathrm{MPMP}}$ ) e interespecífica $\left(\mathrm{B}_{\mathrm{MPT}}\right.$ e $\left.\mathrm{B}_{\mathrm{TMP}}\right)$ foram então utilizados para calcular a competitividade relativa das duas espécies em estudo (C) e o índice de diferenciação de nicho ecológico (IDN).

$$
\begin{aligned}
\text { - } \mathrm{C}_{\mathrm{T}} & =\frac{B_{T T}}{B_{T M P}} \\
\text { - } \mathrm{C}_{\mathrm{MP}} & =\frac{B_{M P M P}}{B_{M P T}} \\
\text { - } \mathrm{IDN} & =\frac{C_{T}}{C_{M P}}
\end{aligned}
$$

\section{RESULTADOS E DISCUSSÃO}

Os resultados do ensaio das monoculturas foram analisados de acordo com a produção final constante. Quando se analisou a biomassa seca das folhas de tomate (Figura 1) e de maria-pretinha (Figura 2), notou-se que, com o aumento da densidade de 0 até 20 plantas $\mathrm{m}^{-2}$, aumentou-se a produção de biomassa seca de 0 a quase $150 \mathrm{~g}$ e de 0 a $105 \mathrm{~g}$, respectivamente. Ao se passar de 20 para 40 plantas $\mathrm{m}^{-2}$, o aumento da produção ainda foi notado, mas em menor taxa. A partir de 40 plantas $\mathrm{m}^{-2}$, a produção praticamente permaneceu constante, estabelecendo-se daí a produção final máxima, que foi de $173,3 \mathrm{~g} \mathrm{~m}^{-2}$ para o tomate e de $130,9 \mathrm{~g} \mathrm{~m}^{-2}$ para a maria-pretinha. As densidades que proporcionaram produção igual a $50 \%$ da produção final foram de 4,16 e 5,17 plantas $\mathrm{m}^{-2}$, respectivamente para tomate e maria-pretinha. Esses valores, também conhecidos como coeficiente $\mathrm{K}_{\mathrm{n}}$, determinam a sensibilidade da espécie à competição intraespecífica (Christoffoleti \& Victoria Filho, 1996).

Comparando as duas espécies, notou-se maior produção final de massa seca de folhas no tomateiro, mas menor coeficiente $\mathrm{K}_{\mathrm{n}}$ para $\mathrm{o}$ tomate, indicando ser esta a espécie mais sensível à competição intra-específica.

Em se tratando da biomassa seca dos caules de tomate (Figura 3) e maria-pretinha (Figura 4), o aumento de 0 para 20 plantas $\mathrm{m}^{-2}$ resultou em aumento linear de 0 para cerca de 170 e 130 g na produção de biomassa seca, respectivamente. De 20 para 40 plantas $\mathrm{m}^{-2}$, o acréscimo na produção não passou de $30 \mathrm{~g}$; a 
partir de 40 plantas $\mathrm{m}^{-2}$, a produção quase foi constante, obtendo-se produção final máxima de $241,58 \mathrm{~g} \mathrm{~m}^{-2}$ para o tomate e $174,59 \mathrm{~g} \mathrm{~m}^{-2}$ para a maria-pretinha, sendo $\mathrm{K}_{\mathrm{n}}$ igual a $10,7 \mathrm{e}$ 4,6 plantas $\mathrm{m}^{-2}$, respectivamente. A densidade correspondente ao $\mathrm{K}_{\mathrm{n}}$ da maria-pretinha foi menor que a do tomate, indicando ser a primeira mais sensivel à competição intra-específica que o último no que se refere à produção de biomassa do caule, mesmo tendo produzido menor biomassa seca final.

Quando se analisou a biomassa seca total, ou seja, biomassas secas de caule e folhas somadas, verificou-se que o aumento de 0 para 20 plantas $\mathrm{m}^{-2}$ provocou aumento linear na

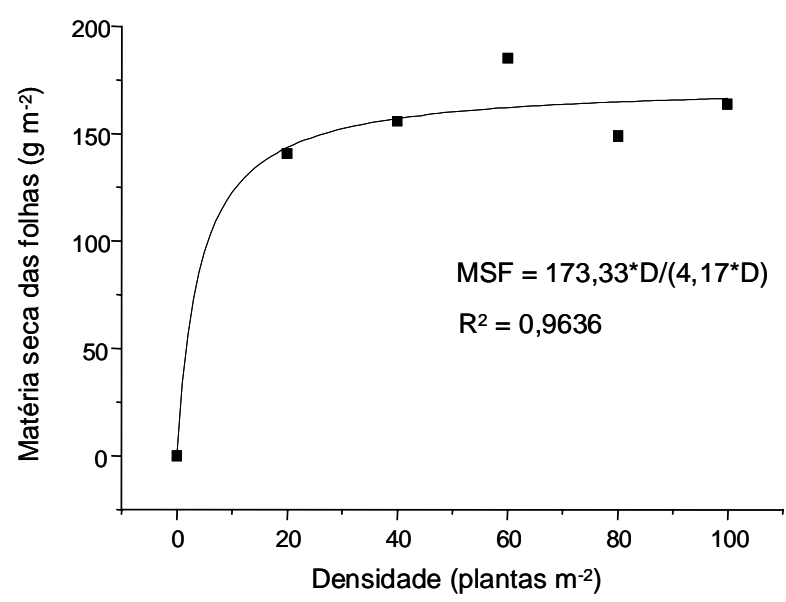

Figura 1 - Resposta da monocultura de tomate representada pela produção de matéria seca das folhas em relação à densidade.

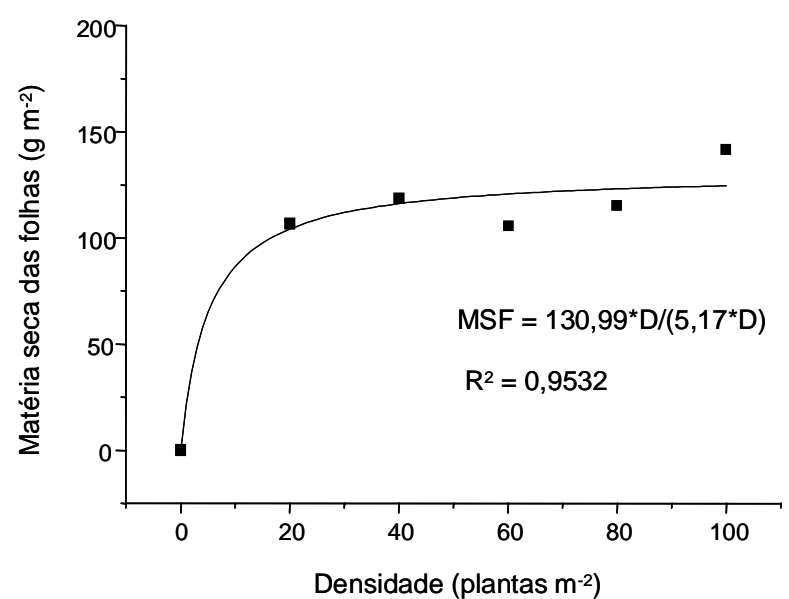

Figura 2 - Resposta da monocultura de maria-pretinha representada pela produção de matéria seca das folhas em relação à densidade.

Planta Daninha, Viçosa-MG, v.20, n.2, p.229-236, 2002 produção de biomassa de 0 para cerca de $310 \mathrm{~g}$ para o tomate (Figura 5) e de 0 para $260 \mathrm{~g}$ para a maria-pretinha (Figura 6). Com o aumento de 20 para 40 plantas $\mathrm{m}^{-2}$, a produção aumentou para 350 e $300 \mathrm{~g}$, respectivamente, mantendo-se praticamente constante a partir de 40 plantas $\mathrm{m}^{-2}$ até se chegar à produção final máxima de aproximadamente 412 e $314 \mathrm{~g} \mathrm{~m}^{-2}$. Os $\mathrm{K}_{\mathrm{n}}$ obtidos foram de 6,4 plantas $\mathrm{m}^{-2}$ para o tomate e 2,7 plantas $\mathrm{m}^{-2}$ para a maria-pretinha.

$\mathrm{O} \mathrm{K}_{\mathrm{n}}$ menor foi o da maria-pretinha, mostrando, portanto, ser esta a espécie mais sensível à competição intra-específica, embora o tomateiro tenha produzido maior biomassa total final.

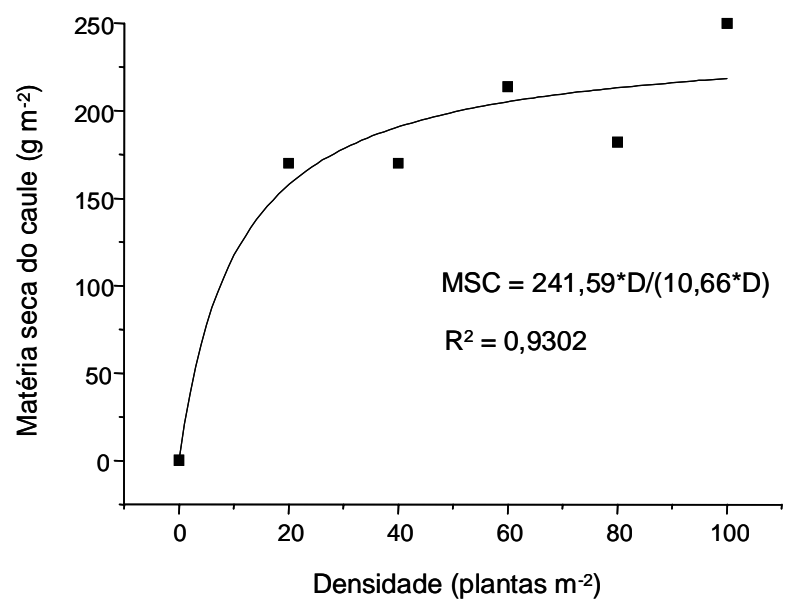

Figura 3 - Resposta da monocultura de tomate representada pela produção de matéria seca do caule em relação à densidade.

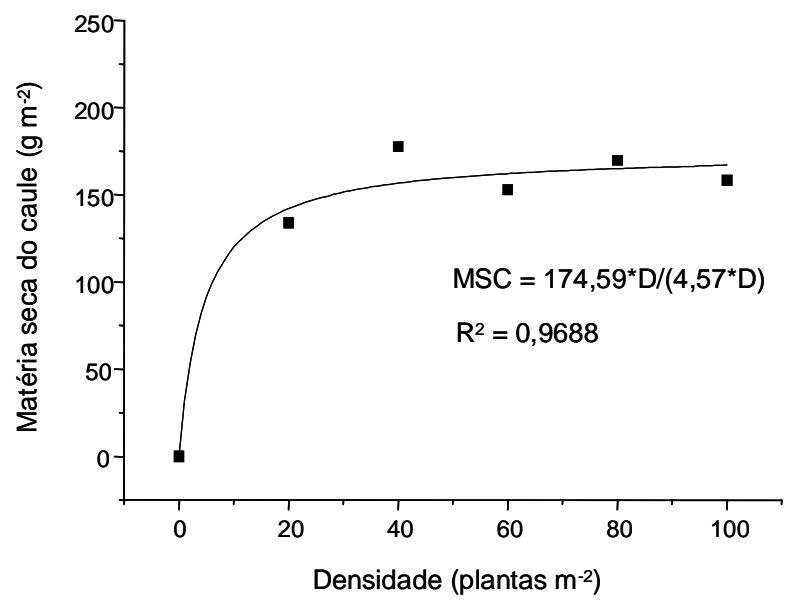

Figura 4 - Resposta da monocultura de maria-pretinha representada pela produção de matéria seca do caule em relação à densidade. 


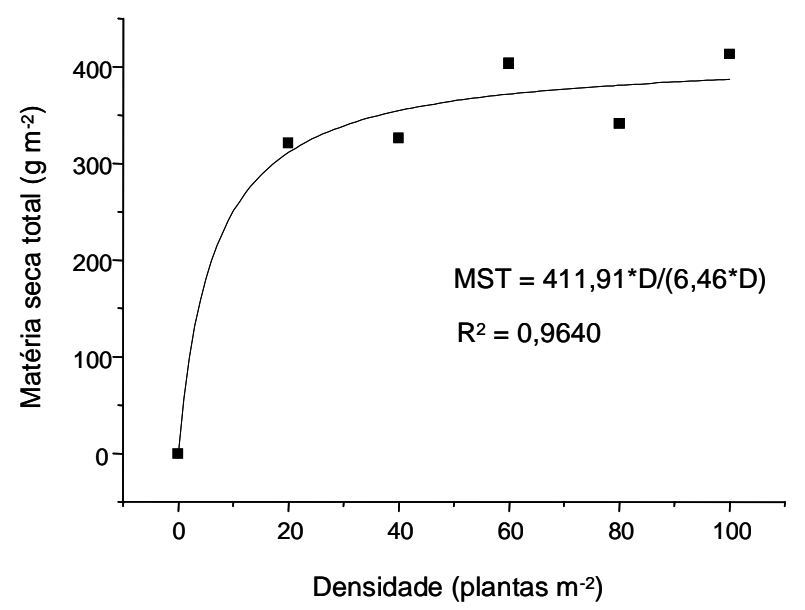

Figura 5 - Resposta da monocultura de tomate representada pela produção de matéria seca total em relação à densidade.

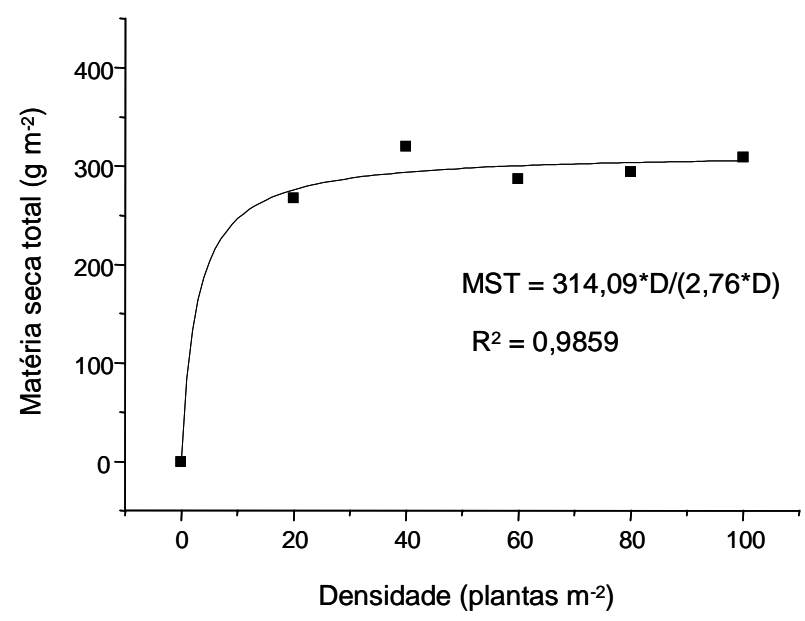

Figura 6 - Resposta da monocultura de maria-pretinha representada pela produção de matéria seca total em relação à densidade.

As folhas se mostraram mais sensiveis aos efeitos da densidade e responderam com maior significância ao aumento do número de plantas $\mathrm{m}^{-2}$, induzindo as plantas de tomate a uma maior sensibilidade à competição intraespecífica. Resultados semelhantes foram obtidos com eucalipto (Dinardo, 1996; Costa, 1999) e café (Dias, 2000).

No entanto, o caule é o parâmetro menos responsivo à variação da densidade, fazendo com que a espécie daninha, no caso a mariapretinha, seja a mais sensivel nesse tipo de competição do que a espécie cultivada, o tomate. Resultados de biomassa da parte aérea obtida por Christoffoleti \& Victoria Filho (1996) mostram o contrário. Naquele experimento, os dois autores obtiveram como mais sensivel à competição intra-específica a espécie cultivada - o milho, sendo a menos sensível o caruru, uma espécie daninha.

Por meio desses resultados, observou-se também que, na densidade de 40 plantas $\mathrm{m}^{-2}$, tanto para o tomate como para a maria-pretinha, a produção obtida foi semelhante à produção máxima, ou seja, densidades acima de 40 plantas $\mathrm{m}^{-2}$ acrescentaram muito pouco à produção final.

Realizou-se o mesmo estudo para as áreas foliares nas duas espécies, constatando-se aumento na área foliar das plantas de tomate (Figura 7) de 0 a quase $3.500 \mathrm{~cm}^{2}$ e de 0 a $3.100 \mathrm{~cm}^{2}$ para a maria-pretinha (Figura 8), ao se aumentar a densidade de 0 para 20 plantas $\mathrm{m}^{-2}$. Ao se passar de 20 para 40 plantas $\mathrm{m}^{-2}$, as áreas foliares praticamente não se alteraram, ficando praticamente constantes até as áreas foliares finais máximas, que foram de $4.195 \mathrm{~cm}^{2} \mathrm{~m}^{-2}$ para o tomate e $4.004 \mathrm{~cm}^{2} \mathrm{~m}^{-2}$ para a maria-pretinha. Os $\mathrm{K}_{\mathrm{n}}$ foram de 2,76 e 6,46 plantas $\mathrm{m}^{-2}$, respectivamente.

O tomate foi a espécie que apresentou maior área foliar final, porém se mostrou mais sensivel à competição intra-específica, apresentando $\mathrm{K}_{\mathrm{n}}$ menor do que o da maria-pretinha, confirmando novamente a maior sensibilidade das folhas aos efeitos da densidade. No entanto, a densidade de 40 plantas $\mathrm{m}^{-2}$ continuou sendo aquela cuja produção se assemelhou à produção máxima nas duas espécies.

Dessa forma, o experimento substitutivo foi instalado com a densidade total de 40 plantas $\mathrm{m}^{-2}$, conforme exigência essencial desse tipo de delineamento experimental (Joliffe et al., 1984).

Foram analisados, visualmente, o gráfico da produção de biomassa seca da parte área e a área foliar das duas espécies em mistura (Figuras 9 e 10, respectivamente). Observouse semelhança com o modelo II descrito em Radosevich (1987), no qual, em comparação com a produção esperada, as curvas de produção e área foliar obtidas pela maria-pretinha mostraram-se convexas e as do tomateiro, côncavas, evidenciando ser a maria-pretinha a espécie que obteve maiores ganhos na mistura. 
Observou-se, também, que os valores de produção e área foliar obtidos na mistura das duas espécies desviaram significativamente das linhas de produção e área foliar esperadas, ou seja, a produção e área foliar das plantas, quando não houve interação competitiva entre as espécies em competição. O tomateiro produziu quantidade de biomassa, bem como apresentou área foliar, abaixo do esperado, enquanto a maria-pretinha produziu acima do esperado, além de apresentar área foliar também acima do esperado. Assim, o tomate é prejudicado pela presença da maria-pretinha, demonstrando ser essa planta daninha um competidor mais agressivo que a planta de tomate. O tomate, por sua vez, prefere uma outra planta de tomate em sua vizinhança, em relação a uma planta de maria-pretinha.

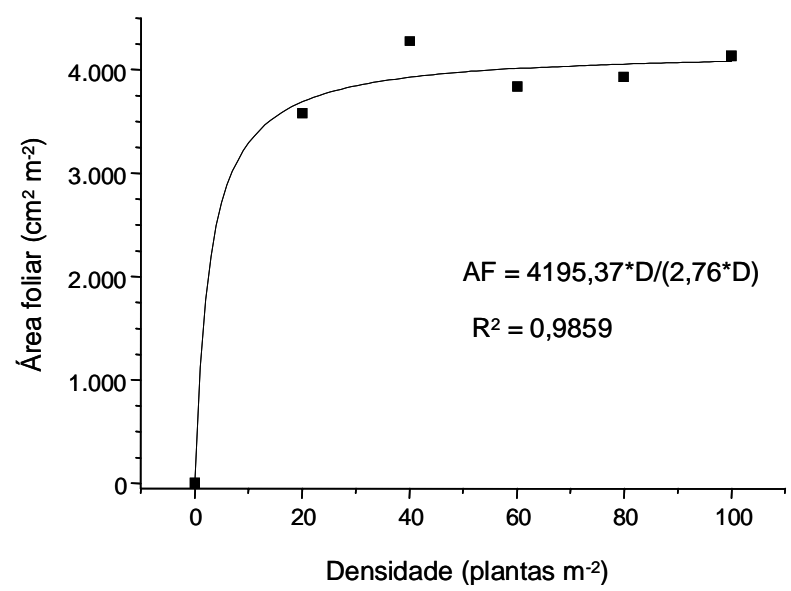

Figura 7 - Resposta da monocultura de tomate representada pela área foliar total em relação à densidade.

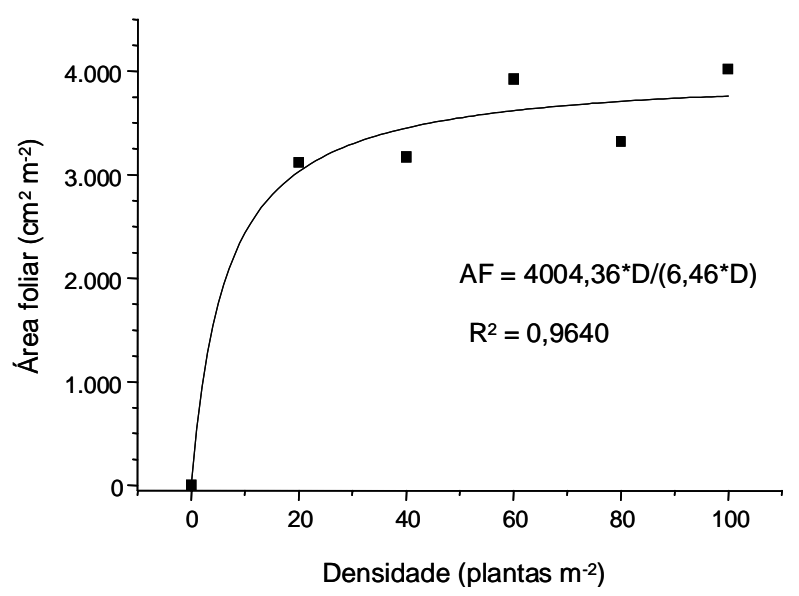

Figura 8 - Resposta da monocultura de maria-pretinha representada pela área foliar total em relação à densidade.

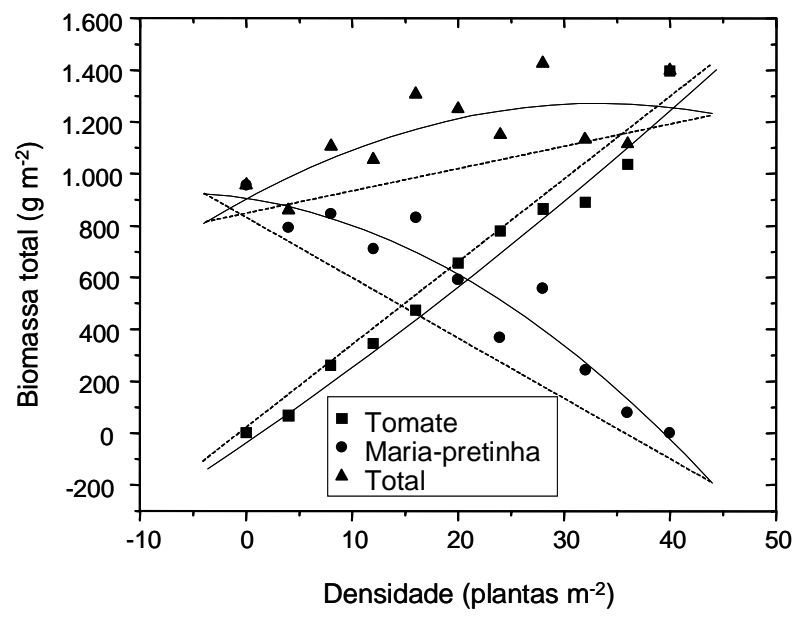

Figura 9 - Resposta da biomassa seca da parte aérea do tomateiro e da maria-pretinha em função da variação da proporção entre as duas espécies. As linhas tracejadas representam a hipótese da não-interação (produção esperada).

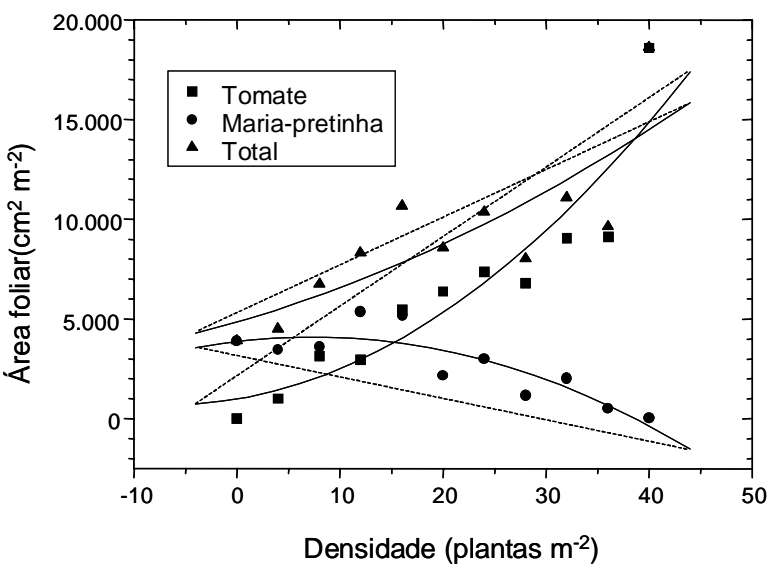

Figura 10 - Resposta da área foliar do tomateiro e da mariapretinha em função da variação da proporção entre as duas espécies. As linhas tracejadas representam a hipótese da não-interação (produção esperada).

Resultado contrário foi obtido por Perez \& Masiunas (1990). Nesse trabalho, a produção total (tomate e maria-pretinha) decresceu à medida que a proporção de maria-pretinha aumentava. Em relação às produções esperadas, a curva da produção da maria-pretinha foi côncava e a do tomateiro convexa, indicando que, na interação entre as duas espécies por recursos comuns, o tomateiro ganhou mais que a maria-pretinha. Ressalta-se, contudo, que os autores trabalharam com outra espécie de maria-pretinha (S. ptycanthum) e outro cultivar de tomate (Heinz 6001). 
As análises das produções recíprocas dos resultados de biomassa e área foliar por planta nos tratamentos do experimento substitutivo, conforme metodologia desenvolvida por Spitters (1983), resultaram nas equações $1,2,3$ e 4, a seguir:

\section{a) Biomassa seca total:}

Tomate: $1 / \mathrm{Y}_{\mathrm{T}}=-0,002443+0.065120\left(1 / \mathrm{D}_{\mathrm{T}}\right)+0.008146\left(1 / \mathrm{D}_{\mathrm{MP}}\right)$

$$
\mathrm{R}^{2}=0,9584
$$

Maria-pretinha: $1 / \mathrm{Y}_{\mathrm{MP}}=-0,007131+0,124329\left(1 / \mathrm{D}_{\mathrm{MP}}\right)+0,027163\left(1 / \mathrm{D}_{\mathrm{T}}\right)$

$$
\mathrm{R}^{2}=0,9503
$$

\section{b) Área foliar:}

Tomate: $1 / \mathrm{Y}_{\mathrm{T}}=-0,000055+0,000282\left(1 / \mathrm{D}_{\mathrm{T}}\right)+0,003916\left(1 / \mathrm{D}_{\mathrm{MP}}\right)$

$$
\mathrm{R}^{2}=0,9807(3)
$$

Maria-pretinha: $1 / \mathrm{Y}_{\mathrm{MP}}=-0,000107+0,000788\left(1 / \mathrm{D}_{\mathrm{MP}}\right)+0,007637\left(1 / \mathrm{D}_{\mathrm{T}}\right)$

$$
\mathrm{R}^{2}=0,9436
$$

Ainda segundo Spitters (1983), os índices de competitividade entre as espécies $\left(\mathrm{C}_{\mathrm{A}}\right.$ e $\left.\mathrm{C}_{\mathrm{B}}\right)$ foram obtidos pelas equações $5,6,7$ e 8 , a seguir:

\section{a) Biomassa seca total:}

Tomate: $\mathrm{C}_{\mathrm{T}}=\frac{0,06512}{0,00815}=7.99$

Maria-pretinha: $\mathrm{C}_{\mathrm{MP}}=\frac{0,124329}{0,027163}=4.58$

Esses índices indicam que uma planta de tomate equivale a 7,99 plantas de mariapretinha ou que 4,58 plantas de tomate correspondem a uma planta de maria-pretinha.

\section{b) Área foliar:}

Tomate: $\mathrm{C}_{\mathrm{T}}=\frac{0,000282}{0,003916}=0,072$

Maria-pretinha: $\mathrm{C}_{\mathrm{MP}}=\frac{0,000788}{0,007637}=0,103$

Para a área foliar, uma planta de tomate equivale a 0,072 planta de maria-pretinha, ou 0,103 planta de tomate corresponde a uma planta de maria-pretinha.

A partir dos índices de competitividade relativa, calcularam-se os indices de diferenciação de nicho ecológico (IDN), apresentados pelas equações 9 e 10. De acordo com Spitters
(1983), IDN > 1 sugere a ocorrência de diferenciação de nicho ecológico para as duas espécies em convivência. Uma vez detectada essa diferenciação de nicho ecológico, pode-se concluir que as espécies produzem mais quando em mistura do que em monocultura.

\section{a) Biomassa seca total:}

$\mathrm{IDN}=\frac{C_{T}}{C_{M P}}=\frac{7,99}{4,58}=1,74$

\section{b) Área foliar:}

$\mathrm{IDN}=\frac{C_{T}}{C_{M P}}=\frac{0,072}{0,103}=0,699$

O resultado obtido na equação 9 demonstrou, pela biomassa seca total, uma diferenciação de nicho ecológico, ou seja, quando as espécies de tomate e maria-pretinha se encontrarem em mistura, estas produzirão maior biomassa seca do que cada uma produzirá em suas respectivas monoculturas.

A equação 10 demonstrou que a área foliar não propiciou diferenciação de nicho ecológico, ou seja, as duas espécies estão competindo pelos fatores ambientais de crescimento que se encontram em quantidades limitantes para o desenvolvimento de ambas. Assim, as duas espécies obterão maiores áreas foliares quando estiverem em monoculturas e não em convivência. 


\section{AGRADECIMENTOS}

À FAPESP e ao CNPq, pela concessão de bolsa de iniciação científica ao primeiro e terceiro autores, respectivamente.

\section{LITERATURA CITADA}

CHRISTOFFOLETI, P. J.; VICTORIA FILHO, R. Efeitos da densidade e proporção de plantas de milho (Zea mays L.) e caruru (Amaranthus retroflexus L.) em competição.

Planta Daninha, v.14, n.1, p.42-47, 1996.

COSTA, A. G. F. Efeito da densidade de plantas de Spermacoce latifolia Aubl. e de Commelina benghalensis L. sobre o crescimento inicial de Eucalyptus grandis W. Hill ex Maiden. Jaboticabal: Universidade Estadual de São Paulo, 1999. p. 54 (Trabalho de graduação).

DIAS, G. F. S. Efeito da densidade de plantas de Brachiaria decumbens Stapf. sobre o crescimento inicial de mudas de Coffea arabica $\mathbf{L}$. Jaboticabal: Universidade Estadual de São Paulo, 2000. p. 50 (Trabalho de graduação).

DINARDO, W. Efeito da densidade de plantas de Brachiaria decumbens Stapf. e Panicum maximum Jacq. sobre o crescimento inicial de mudas de Eucalyptus grandis W. Hill ex Maiden. Jaboticabal: Universidade Estadual de São Paulo, 1996. p. 90 (Trabalho de graduação).

HARPER, J. L. Mixtures of species. In: HARPER, J. L. The population biology of plants. New York: Academic Press, 1977. p. 237-304.

JOLIFFE, P. A.; NINJAS, A. N.; RUNECKLES, V. C. A reinterpretation of yield relationships in replacement series experiments. Journal of Applied Ecology, v. 21, p. 227243, 1984.
McGILCHRIST, C. A.; TRENBATH, B. R. A revised analysis of plant competition experiments. Biometrics, v. 27, p. 659-671, 1974.

PEREZ, F. G. M.; MASIUNAS, J. B. Eastern black nightshade (Solanum ptycanthum) interference in processing tomato (Lycopersicon esculentum). Weed Sci., v. 38, p. $385-388,1990$.

PITELLI, R. A. Competição e controle de plantas daninhas em áreas agrícolas. IPEF, v. 4, n. 12, p. 25-35, 1987.

PITELLI, R. A.; KARAM, D. Ecologia de plantas daninhas e a sua interferência em culturas florestais. In: SEMINÁRIO TÉCNICO SOBRE PLANTAS DANINHAS E O USO DE HERBICIDAS EM REFLORESTAMENTO, 1., 1988, Rio de Janeiro. Anais... Rio de Janeiro: 1988. p. 44-64.

RADOSEVICH, S. R. Methods to study interactions among crops and weeds. Weed Technol., v. 1, p. 190-198, 1987.

ROUSH, M. L. et al. A comparison of methods for measuring effects of density and proportion in plant competition experiments. Weed Sci., v. 37, n. 2, p. 268$275,1989$.

SPITTERS, C. J. T. An alternative approach to analysis of mixed cropping experiments. I. Estimation of competition effects. Nether. J. Agric. Sci., v. 31, p. 1-11, 1983.

WIT, C. T. On competition. Verslagen Landbouw Onderzoek., v. 66, n. 8, p. 1-82, 1960.

WIT, C. T.; VAN DEN BERGH, J. P. Competition between herbage plants. Nether. J. Agric. Sci., v. 13, p. 212-221, 1965. 